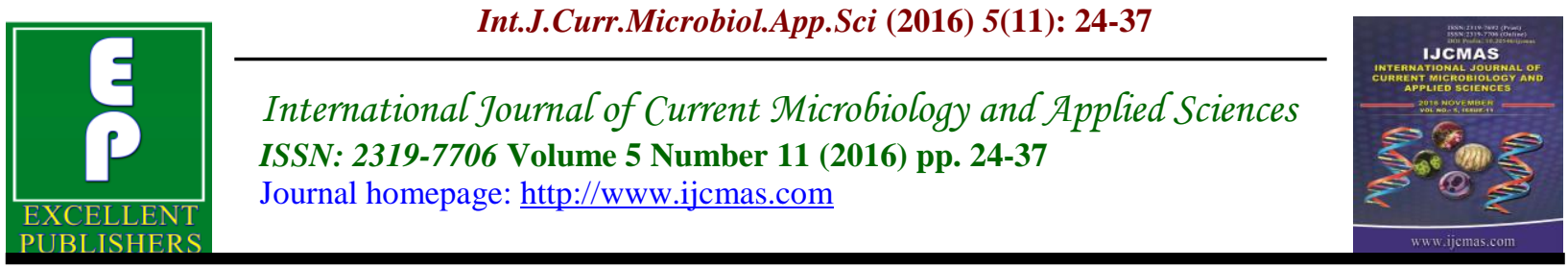

Original Research Article

http://dx.doi.org/10.20546/ijcmas.2016.511.003

\title{
Development of RTE Millet Mixes with Dehydrated Vegetable Peel
}

\author{
R. Balasasirekha* and P. Santhoshini \\ Department of Food Science and Nutrition, Avinashilingam Institute for Home Science and \\ Higher Education for Women, Coimbatore - 641 043, Tamil Nadu, India \\ *Corresponding author
}

Keywords

Cucumber,

Potato peels, tray drying,

RTE mix, barnyard, foxtail, sorghum, little millet.

\section{Article Info}

Accepted:

04 October 2016

Available Online:

10 November 2016

\section{A B S T R A C T}

Reduced vegetable consumption leads to poor health and increased risk of non communicable diseases. Consuming a variety of vegetables along with millets contributes significantly to nutrition security. Hence the study was aimed at evaluation of millet based RTE mix recipes incorporated with dehydrated vegetable peel. The vegetables namely potato and cucumber were subjected to different dehydration methods namely tray drying, microwave drying and sun drying. RTE millet mixes formulated include adai mix, vegetable pulav mix and chapathi mix using millets like barnyard, foxtail, little and sorghum. The nutrient analysis of different dehydration methods revealed that tray dried sample had maximum retention of nutrients and hence chosen for incorporation into RTE mixes. The phytic acid levels in tray dried vegetable peels was also well below the upper limit. The level of incorporation of tray dried fruit peels was at 5,10 and 15 per cent with variation 1,2 and 3 respectively. The developed recipes were subjected to organoleptic evaluation. The results indicated that RTE millet recipes incorporated with tray dried vegetable peels were well accepted at 5 per cent level of incorporation. The millet - vegetable peel combo RTE mix is nutrient rich and packed with anti-oxidants and phytochemicals.

\section{Introduction}

Vegetables form an important component in our daily diet. Reduced fruit and vegetable consumption is linked to poor health and increased risk of Non Communicable Diseases (NCDs). An estimated 5.2 million deaths worldwide were attributable to inadequate fruit and vegetable consumption. Vegetables are rich sources of vitamins and minerals, dietary fibre and a host of beneficial non-nutrient substances including plant sterols, flavonoids and other antioxidants. Consuming a variety of vegetables help to ensure an adequate intake of any of these essential nutrients. WHO (2013) suggests consumption of more than 400 grams of fruits and vegetables per day improves overall health and reduces the risk of certain NCDs (www.who.int).

Fruit and vegetable wastes and their byproducts, exert an influence on environment and need to be managed and/or utilized. They are very rich in bioactive components, which are considered to have a beneficial effect on health. For the last decade, efforts have been made to improve methods and 
ways of reusing fruits and vegetables wastes (Chodak et al., 2007). In olden days people were healthy enough to do their household activities and free from diseases/illness due to the consumption of more varieties of minor millets, which is lacking in the present day scenario. Hence consuming these minor millets is of great importance to lead a disease free life. The presence of all the required nutrients in millets makes them suitable for large scale utilization in the manufacture of food products, such as baby foods, snack foods and ready to eat foods. Increasing more millet products have entered into the daily lives of people including millet porridge, millet wine and millet nutrition powder from both grain and flour form (Subramanian and Viswanathan, 2007; Liu et al., 2011). Inclusion of these millets in the daily plate with vegetables can add bulk and nutritive value to our diet. But vegetables perish quickly because of high moisture content and/or due to the seasonal availability they can be used in the preserved forms. The vegetables can be preserved in many ways. The peels has high nutritive value and a potential antioxidant can also be preserved and used effectively. One such method of preservation is drying, an age old technique.

Drying is a process of dehumidification in which moisture is removed from a solid using thermal energy. In the design of a drying system, product quality, economic viabty and environmental concerns should be taken into consideration (Hawlader et al., 2013). Convenience food is perceived expensive by people besides being out-ofway meals in Indian culture. In today's scenario, convenience food industry is getting adapted to Indian type of requirements and is growing leaps and bounds in India. The working women also are not shy to explore these convenience foods into their kitchen (Takhellamban and
Chimmad, 2015). Convenience foods offer many benefits, including less time spent planning meals and grocery shopping, less preparation time, fewer leftovers (with single portion foods) and easier cleanup (Minton, 2012).

A fast paced urban lifestyle, increasing dominance of nuclear family structure, rising disposable income, convenience of use have made RTE foods popular. Provision of such RTE foods based on nutritious grains such as millets would be more meaningful in the modern times in the management of life style disorders (Takhellamban et al., 2015). Considering the above mentioned nutritional and health benefits of millets, vegetables and importance of RTE mixes, the present investigation was carried out with the following objectives:

- Dehydration of the selected vegetable peels using different dehydration methods

- Analysis of the nutritive value of the fresh and dehydrated vegetable peels

- Selection of millets and recipes

- Development and standardization of millet based RTE mixes

- Incorporation of dehydrated peels into the standardized RTE mix

- Sensory evaluation of the developed millet based RTE mixes

\section{Materials and Methods}

Standardization of the dehydration
methods and nutrient analysis of
vegetable peel

\section{Selection and procurement of vegetables}

Fruits and vegetables are low fat and low energy dense foods, relatively rich in vitamins, minerals and other bioactive 
compounds and a good source of fibre. They are essential to maintain proper body functions (Dowell et al., 2009). After a thorough study of the available reviews and literature on vegetables nutritive value, two fruits namely, potato (Solanum tuberosum) and cucumber (Cucumis sativus) having more nutrients such as vitamins, minerals, fiber and phytochemicals-carotenoids, flavonoids, limonoids and polyphenols which appear to have biological activities and health benefits were selected. Mature, fresh, intact vegetables with no bruises namely potato and cucmber were procured in bulk quantity from the pazhamudir nizhayam.

\section{Selection and standardization of dehydrated methods}

Dehydration is an ancient process of preserving foods and a complex operation involving transient transfer of heat and mass along with several rate processes, such as physical or chemical transformations, which, in turn, may cause changes in product quality (Mujumdar and $\mathrm{Wu}$, 2008). The dehydration methods selected include tray drying, microwave drying and sun drying. $500 \mathrm{~g}$ of fresh vegetables were taken for dehydration of samples. Selected vegetables namely cucumber and potato were washed under running tap water thoroughly to remove the presence of mud and dust particles present on the upper layer of the skin. The skin was then peeled off using a peeler in a clean plate.

\section{Tray drying}

Tray drying or cabinet drying is a dehydration technique where dehydration of the sample is carried out at a low temperature under reduced pressure (Rahuramulu et al., 2003). Potato peels and cucumber peels were cut into pieces of 1.5 $\mathrm{cm}$ length and had thickness of $0.5 \mathrm{~mm}$. The two vegetable peels were kept in trays at a temperature of $50^{\circ} \mathrm{C}$ and dehydrated separately. Potato and cucumber peels took 15 hours to dehydrate. The color of the peels turned to a darker shade after dehydration.

\section{Microwave drying}

Microwave drying is a conventional method where heat is passed over the food sample which reduce the moisture content in food thereby drying the food. Potato and cucumber peels were subjected to microwave drying. The temperature was maintained at $40^{\circ} \mathrm{C}$. The microwave oven was preheated for 6 minutes. Potato and cucumber peels took 24 minutes to dehydrate. The dehydrated fruit peels were stored in air tight zip lock covers and labelled. The color of the microwave dried peels remained same after dehydration.

\section{Sun drying}

Sun drying is one of the slow and gentle drying technique which gives the product its characteristic taste, color and flavor. The process of sun drying depends on the intensity of the sunlight which allows the product to reach optimum moisture and quality levels. Sun drying was done between $10 \mathrm{am}$ to $3 \mathrm{pm}$. The vegetable peels were placed in clean plates and were covered using perforated polyethylene cover to prevent it from sweating. Cucumber and potato peels were cut into $1.5 \mathrm{~cm}$ length and dehydrated for 5 consecutive days. The temperature varied between $30^{\circ} \mathrm{C}$ to $32^{\circ} \mathrm{C}$ on these days. All the peels were dehydrated until the moisture content reduced to less than 10 per cent. Sun dried samples almost retained the same color compared to other two dehydration methods.

All the dehydration methods were standardized by altering the time and temperature and were done in triplicates. 


\section{Analysis of anti-nutritional substances in vegetable peels}

Anti-nutrients are substances that are damaging to health, they include metals such as lead, calcium and mercury, their presence in the body uses up large amount of nutrients such as zinc, calcium, vitamin and other anti-oxidants to neutralize them. Phytic acid is an antinutrient that interferes with the absorption of minerals from the diet (Beecher, 2003). The tray dried vegetable peels had maximum retention of nutrients. Hence, these tray dried dehydrated peels were chosen for incorporating into the RTE mix. Also tray dried vegetable peels were analyzed for the presence of anti-nutritional factor namely phytic acid.

\section{Development of RTE millet mixes using dehydrated vegetable peels}

\section{Selection of millets}

Millets have great potential for being utilized in different food systems by virtue of their nutritional quality and economic importance and are rich in phytochemicals, fiber and minerals (Nazneen et al., 2012). Based on the nutritional importance of millets, four millets namely cholam (Soghum bicolour), kuthiraivali (Echinochoa colona), thinai (Setaria italica) and samai (Panicum sumatrense) rich in nutrients were selected. The selected millet grains were procured from super market and cleaned to separate sand grits and other heavy particles. They were stored in air tight containers for further use. The millets with their local and botanical names is presented in Table I.

\section{Selection of recipes}

In India $3+2$ food pattern is followed. i.e. three heavy meals and two snacks. Hence three recipes one each from breakfast, lunch and dinner was selected for the study. The recipe for breakfast include adai, for lunch vegetable pulav and for dinner chappati. All these recipes were standardized by altering the quantity of ingredients used in the formula. To the standardized recipe, the tray dried dehydrated peels were incorporated at three levels. Based on the type of recipe selected and the texture of the mix, millets were either brokened or powdered and sieved. For adai mix, coarse powder and for chappati mix, millet grains were used in the form of powder. The powder was sieved in a 40 mesh sieve of $0.42 \mathrm{~mm}$ and was incorporated into the chappati mix. For vegetable pulav, millet grains were cleaned and used as such.

\section{Formulation of millet based RTE mix}

The RTE mixes for the three commonly consumed recipes namely adai, vegetable pulav and chappati were standardized. The procedure for recipe preparation in the study was standardized based on the procedure followed by RCT (Ramaswamy Chinnammal Trust) food industry in Coimbatore. To prepare RTE millet mix, weighed quantities of the ingredients were taken, dry roasted the ingredients separately in a pan, for a stipulated time and mixed. The mix was allowed to cool. The method i.e. the time taken for roasting the ingredients was standardized. The recipes were standardized by altering the quantity of ingredients in the standard recipe such that the dehydrated peels blend into the mix.

The millet adai mix consisted $100 \mathrm{~g}$ each of the four coarsely powdered millets namely, barnyard millet, foxtail millet, sorghum, little millet and $150 \mathrm{~g}$ each of green gram dhal and Bengal gram dhal and $130 \mathrm{~g}$ of rice along with salt and chillies to taste. The millet vegetable pulav mix consisted $200 \mathrm{~g}$ each of the four millets namely, barnyard millet, foxtail millet, sorghum, little millet and dehydrated vegetables carrot and beans 
along with the spices and seasonings. The millet chappati mix consisted $125 \mathrm{~g}$ each of the four millet flour namely, barnyard, foxtail, sorghum, little millet and equal i.e. $500 \mathrm{~g}$ of wheat flour.

Incorporation of dehydrated vegetable peels into standardized RTE mix

The dehydrated vegetable peels were incorporated into the standardized RTE millet mix in varying proportions. The dehydrated vegetable peels were incorporated at three levels namely, 5, 10 and 15 per cent into the developed RTE millet mix. The tray dried peels were powdered and added into the RTE chappati mix, as coarse powder into RTE adai mix and as whole millet grains into the RTE vegetable pulav mix. Variation I contains $5 \mathrm{~g}$ of dehydrated peel and $95 \mathrm{~g}$ of millet mix; variation II contains $10 \mathrm{~g}$ of dehydrated peel and $90 \mathrm{~g}$ of millet mix and variation III contains $15 \mathrm{~g}$ of dehydrated peel and $85 \mathrm{~g}$ of millet mix. All the developed RTE mixes were standardized and evaluated sensorily.

\section{Sensory Evaluation of the dehydrated peel incorporated RTE mix}

The vegetable peel incorporated RTE millet mix were evaluated sensorily. Twenty semi trained panelists from Avinashilingam University were selected for sensory evaluation. Sensory evaluation was carried out using 9 point hedonic scale for all the sensory characteristics namely appearance, flavor, texture, taste, color and overall acceptability. Scoring 9 to 0 corresponds to like very much to dislike very much. The prepared recipes were evaluated sensorily at $3.30 \mathrm{pm}$.

\section{Statistical analysis and interpretation of the results}

The data obtained for sensory attributes of the developed recipes with three variations was analyzed statistically and interpreted. The data was consolidated and tabulated in which mean and standard deviation were computed.

The research design and the protocol used in the study were submitted for scrutinisation and approval to the Institutional Human Ethics Committee and ethical clearance approval was obtained.

\section{Results and Discussion}

\section{Dehydration characteristics of the vegetable peels}

The vegetables selected namely potato and cucumber were dehydrated using three dehydration methods, namely tray drying, microwave drying and sun drying to a residual moisture content below 10 per cent. The duration and temperature of drying are among the most important factors which affect the physical, chemical, microbiological and nutritional characteristics of the dehydrated products.

\section{Anti-nutritional substance in dehydrated vegetable peels}

Anti-nutrients are substances that cause damage to health. They include metals such as lead, calcium and mercury. In this study anti-nutritional substance namely phytic acid present in selected dehydrated vegetables was analyzed. Phytic acid is an anti-nutrient that interferes with the absorption of minerals from diet (Shi et al., 2003).

The peels of tray dried vegetable samples had maximum retention of nutrients. Hence anti-nutritional substance namely phytic acid was analyzed only for tray dried samples. It was seen that potato had $39 \mathrm{mg}$ and cucumber with $10 \mathrm{mg}$ of phytic acid per $100 \mathrm{~g}$ of dehydrated peels. The safe upper limit of phytic acid was found to be $37 \mathrm{mg}$ 
and $20 \mathrm{mg}$ for potato and cucumber respectively. The values obtained in the present study are safe within the upper limits and hence can be incorporated in the RTE mix.

\section{Organoleptic evaluation of the RTE millet recipes incorporated with tray dried peel powder}

The only way to evaluate sensory quality or some of its attributes is to ask their opinion, since sensory quality is not an intrinsic food characteristic, but the result of interactions between humankind and food. The analysis of the chemical composition and the physical properties of a certain food product affords information about the nature of stimuli perceived by the consumer, but not about the sensation experienced in its consumption (Brandt et al., 2003).

Three popular, traditional recipes which were consumed regularly in the normal diet were selected for the incorporation of dehydrated vegetable peels. The recipes selected were adai, vegetable pulav and chappati. These recipes are easy to prepare and are either protein, fiber or energy rich. All the recipes were incorporated with tray dried peels. An incorporation level of 5, 10 and 15 per cent, were chosen each for adai, vegetable pulav and chappati.

Acceptability of the food is also an important criteria in any situation. Therefore, acceptability trials of the developed recipes were done. The developed recipes were subjected to sensory evaluation by 20 semi trained panelists. The various parameters based on which the recipes were tested by panelists was appearance, color, taste, flavor and texture. A nine point hedonic scale was chosen for the evaluation. The overall acceptability for each recipe was assessed by considering the different criteria for sensory evaluation.

Organoleptic evaluation of tray dried potato peel incorporated RTE adai mix

Adai prepared from standard and variations 1,2 and 3 incorporated with tray dried potato peel showed that in terms of appearance, variation 1 and 2 have no significant difference. Standard and variation 3 had a decreased value of 8.2 and 7.4 respectively. In terms of color, standard and three variations got scores between 6.80 to 8.10. Standard had maximum score of 8.10. Taste is an important attribute contribute scores from 6.80 to 8.45 . The maximum mean value obtained was for variation 1 with 8.5 . The scores obtained for flavor in adai ranged from 6.90 to 8.60 , the maximum obtained for variation 1 with 8.60 . With regard to texture standard showed the best score with mean value of 8.10 . In terms of scores obtained for overall acceptability standard obtained scores 8.50 followed by variation 1 with 8.20 , variation 2 with 7.40 and variation 3 with 6.80 (Table II).

Organoleptic evaluation of tray dried potato peel incorporated RTE vegetable pulav mix

Table III depicts the organoleptic evaluation of millet vegetable pulav prepared with tray dried potato peel. It was found that the appearance of vegetable pulav prepared from tray dried potato peel standard and variations 1, 2 and 3. Standard scored best result with mean value of 8.20. Variation 3 scored a decreased score of 6.65. In terms of color, standard and three variations got scores between 6.55 to 7.80.Variation 1 and 2 had mean value of 6.70 each. The maximum mean score for color was for standard with 7.8. Taste contributes scores from 5.95 to 7.60 . The 
maximum mean value obtained for standard was 7.60 followed by variation 3 with 6.55 , variation 2 with 6.10 and variation 1 with 5.95 . The scores obtained for flavor ranged from 6.05 to 7.65 , the minimum score 6.05 for variation $1,6.30$ for variation $3,6.65$ for variation 2 and 7.65 for standard. With regard to texture, standard showed the best result with mean value of 7.70 followed by variation 1 with 7.35 , variation 2 with 6.50 and variation 3 with 6.10 respectively. Overall acceptability of standard obtained was 7.65 followed by variation 1 with 7.00 , variation 2 with 6.70 and variation 3 with 6.40 .

Organoleptic evaluation of tray dried potato peel incorporated RTE chappati mix

Regarding to the appearance of chappati prepared with tray dried potato peel, the score was 7.95 for standard; 6.90 for variation $1 ; 7.40$ for variation 2 and 7.20 for variation 3. Color contributes scores from 6.95 to 7.45 . The maximum mean value was 7.60 obtained for variation 2 followed by 7.45 for variation $1,7.25$ for standard and 6.95 for variation 3 . The minimum mean value obtained was 6.60 for variation 1 and 3, 6.80 for variation 2 and 7.65 for standard for taste respectively. In terms flavor, variation 2 got 6.60 the least, variation 1 and 3 got 6.90 , standard got 7.55 respectively. Texture ranged from 6.10 to 7.15 .

Variation 1 with 5 per cent incorporation got maximum mean value of 7.15 followed by variation 2 with 7 , standard with 6.90 and variation 3 with 6.10 . The mean values obtained for overall acceptability of standard was 7.90, variation 1 with 7.05 , variation 2 with 7.20 and variation 3 with 6.10 respectively (Table IV).
Organoleptic evaluation of tray dried cucumber peel incorporated RTE adai mix

Adai prepared from standard mix and with tray dried cucumber peel incorporated variations 1, 2 and 3 showed that in terms of appearance, variation 1 and 2 incorporated with 5 per cent and 10 per cent dehydrated cucumber peel respectively scored best with a mean score of 8.15 each. Color is one attribute essential for acceptability. In terms of color variation 1 and standard had a maximum score of 8.35 and 8.15 respectively. The scores obtained for flavor in adai ranged from 6.60 to 8.20 , the maximum mean value is obtained from standard with 8.20 followed by variation 2 with 8 , variation 1 with 7.70 and variation 3 with 6.60 respectively. Taste is an important attribute for sensory evaluation, taste contribute scores from 6.70 to 8.15 and maximum being in variation 1 with 8.35 . This was followed by standard, variation 2 and variation 3 . With regard to flavor and texture standard showed best result with mean score of 8.20 and 8.10 respectively. In terms of scores obtained for overall acceptability, variation 1 obtained 8.25 followed by variation 2 with 8.15, standard with 8.05 and variation 3 with 6.80 (Table V).

Organoleptic evaluation of tray dried cucumber peel incorporated RTE vegetable pulav mix

The sensory scores of vegetable pulav prepared with tray dried cucumber peel showed in terms of appearance ranged from 6.55 to 8.45 . The maximum mean value obtained from variation 1 with 8.45 followed by 8.35 for standard, 6.75 for variation 2 and 6.55 for variation 3 . The color of variation 1 was highest with 8.50 whereas it was 8.45 for standard. This 
was followed by 6.90 for variation 2 and 6.60 for variation 3 . The mean scores of taste was 8.40, 8.45, 6.90 and 6.55 for standard, variation 1 , variation 2 and variation 3 respectively. In terms of flavor it was observed that the minimum mean value obtained 6.05 for variation 3 with 15 per cent incorporation. This was followed by 7.15 for variation $2,8.45$ for variation 1 and 8.65 for standard. Texture of standard, variation 1 , variation 2 and variation 3 was $8.35,8.20,6.60$ and 6.40 respectively. The mean overall acceptability score was 8.43 for standard; 8.35 for variation $1 ; 7.15$ for variation 2 and 5.90 for variation 3 respectively (Table VI).

\section{Organoleptic evaluation of tray dried cucumber peel incorporated RTE chappati mix}

The sensory scores of the dehydrated cucumber peel incorporated chappati showed an appearance, color, taste, flavor, texture and overall acceptability. In terms of appearance, standard scored best with a mean score of 7.75 followed by variation 1 with 7.30, variation 3 with 7.20 and variation 2 with 6.75 . In terms of color, variation 3 had minimum scores of 6.70 followed by variation 1 with 6.95 , variation 2 with 7.40 and standard with 7.85 . The scores obtained for flavor in chappati ranged from 6.80 to 7.70 , the maximum obtained by standard with 7.70. Taste is an important attribute. Taste contribute scores from 6.40 to 8.05 and maximum being in standard with 8.05 followed by variation 1 with 7.20, variation 2 with 6.80 and variation 3 with 6.40. Regarding texture, mean scores of standard showed a value of 7.30 , variation 1 with 7.25 , variation 2 with 6.90 and variation 3 with 6.60 respectively. In terms of overall acceptability, standard obtained 7.45 followed by variation 2 with 7.00 mean scores. Variation 1 with 6.90 scores and variation 3 with 6.55 respectively
(Table VII).

Overall acceptability of RTE millet mix
incorporated with tray dried samples

Table VIII reveals the overall acceptability of RTE millet mix incorporated with tray dried fruit and vegetable peels. The overall acceptability of adai prepared from tray dried potato peel showed a score of that 8.50 for standard with maximum score followed by variation 1 with 8.20 , variation 2 with 7.40 and variation 3 with 6.80 . For vegetable pulav, prepared from tray dried potato peel, standard got maximum mean value of 7.65 , variation 1 got 7.00, variation 2 got 6.70 and variation 3 got 6.40. The mean value obtained for overall acceptability of chappati prepared from tray dried potato peel, had a score maximum of 7.90 for standard followed by variation 1 with 7.05, variation 2 with 7.20 and variation 3 with 6.10 respectively.

The overall acceptability obtained for adai prepared from cucumber peel, variation 1 got mean value of 8.25 , variation 2 got 8.15 , standard got 8.05 and variation 3 got 6.80 respectively. The overall acceptability of vegetable pulav secured 8.43 for standard, 8.35 for variation $1,7.15$ for variation 2 and 5.90 for variation 3. Regarding the overall acceptability of chappati prepared from tray dried cucumber peel, standard obtained 7.45 followed by variation 2 with 7.00, variation 1 with 6.90 and variation 3 with 6.55 respectively.

The overall result indicates that variation 1 with 5 per cent incorporated tray dried vegetable peel powder had an overall acceptability when compared with variation 2 and 3. Hence this level of incorporation can be included in the daily dietaries. This may enhance the nutraceutical potential of the food consumed. 
Conventional drying (hot air) offers dehydrated products that can have an extended life of an year. Drying is one of the most cost-effective ways of preserving foods of all variety which involves removal of water by application of heat. A variety of food sub- types are preserved using drying, these include: marine products, meat products as well as all fruits and vegetables. Food products can have moisture content as high as $90 \%$ or more which needs to be reduced to an acceptable value so as to avoid microbial growth (Mujumdar and Wu, 2008). Dried fruits and other dried products are considered rich in energy, minerals and vitamins and are generally regarded as nutrient dense foods (Sablani, 2006). Zhang (2009) showed that Microwave (MW)-related (MW-assisted or MW-enhanced) combination drying is a rapid dehydration technique that can be applied to specific foods, particularly to fruits and vegetables. Freeze drying is the best way to dehydrate most of the food products. Loss of volatiles is another important issue in drying of high valued fruits, spices, etc and needs to be handled properly but in a cost effective manner (Jangam et al., 2010).

Air convection drier is one of the most widely used methods of drying. Hot air drying uses air with elevated temperature to dry the products. A study done by Abascal et al., 2005 showed that oven drying at $30^{\circ} \mathrm{C}$ did not caused a marked loss of volatile compound. Sun drying is the oldest and most economical drying method. Energy consumption and dried product quality are critical parameters in the selection of drying process. Recently, due to increased prices and shortage of fossil fuels as well as of adverse impact on the environment, emphasis on the use of solar energy as an alternative energy source for dehydration (Tripathy and Kumar, 2009).

Tasirin et al., (2014) reported higher limonene in fluidized bed dried samples of orange peel compared to those of sun dried peels. Fluidized bed drying preserved 80 per cent of the vitamin $C$ content whereas the sun drying preserved only 50 per cent of the total vitamin $\mathrm{C}$. Velazquez et al., (2014) studied sun drying with oven drying and reported that sun dried paprika were more associated with microbial proliferation and quality losses. A study done by Henriquez et al., (2012) showed that drum drying retained 30 per cent of the phenolics in apple peel. A study done by Rajchert et al., (2015) showed that lyophilized cranberries has approximately 8 per cent higher anthocyanin pigment than those dried by convective fluidized bed drying. Increase in air drying temperature from 40 to $60^{\circ} \mathrm{C}$ significantly reduced total phenolic and flavonoid content of lemon peel (Nesrine et al., 2015).

Table.1 Local name, botanical name and other names of the selected millets

\begin{tabular}{|c|c|l|}
\hline Local name & Botanical name & \multicolumn{1}{|c|}{ Other names } \\
\hline Cholam & Sorghum bicolor & Jowar, Jowari, Juar, Jola, \\
\hline Kuthiraivali & Echinochooa colona & $\begin{array}{l}\text { Shyama, Sanwa, Oodalu, Khira, Swank, Udalu, } \\
\text { Kodisama }\end{array}$ \\
\hline Thinai & Setaria itallica & $\begin{array}{l}\text { Kaon, Kang, Kakum, Navane, Kang, Rala, } \\
\text { Kanghu, Kangam, Kora, Kangni, Korra }\end{array}$ \\
\hline Samai & Panicum sumatrense & $\begin{array}{l}\text { Sama, Gajro, Kuri, Kutki, Shaven, Sava, Halvi, Vari, } \\
\text { Suan, Samalu }\end{array}$ \\
\hline
\end{tabular}


Table.2 Organoleptic evaluation of potato peel adai RTE millet mix

\begin{tabular}{|c|c|c|c|c|}
\hline Criteria & Standard & Variation 1 & Variation 2 & Variation 3 \\
\hline Appearance & $8.20 \pm 0.72$ & $8.10 \pm 0.64$ & $8.10 \pm 0.72$ & $7.40 \pm 0.82$ \\
\hline Color & $8.10 \pm 0.62$ & $8.3 \pm 0.69$ & $7.65 \pm 0.59$ & $6.80 \pm 0.62$ \\
\hline Taste & $8.45 \pm 0.60$ & $8.50 \pm 0.51$ & $7.40 \pm 0.75$ & $6.80 \pm 0.77$ \\
\hline Flavor & $8.40 \pm 0.68$ & $8.60 \pm 0.50$ & $7.50 \pm 0.61$ & $6.90 \pm 0.64$ \\
\hline Texture & $8.10 \pm 0.64$ & $8.00 \pm 0.56$ & $7.30 \pm 0.57$ & $6.95 \pm 0.76$ \\
\hline $\begin{array}{c}\text { Over all } \\
\text { acceptability }\end{array}$ & $8.50 \pm 0.61$ & $8.20 \pm 0.62$ & $7.40 \pm 0.88$ & $6.80 \pm 0.89$ \\
\hline
\end{tabular}

Table.3 Organoleptic evaluation of potato peel vegetable pulav RTE millet mix

\begin{tabular}{|c|c|c|c|c|}
\hline Criteria & Standard & Variation 1 & Variation 2 & Variation 3 \\
\hline Appearance & $8.20 \pm 0.52$ & $7.45 \pm 0.94$ & $6.85 \pm 0.93$ & $6.65 \pm 0.81$ \\
\hline Color & $7.80 \pm 0.52$ & $6.70 \pm 0.73$ & $6.70 \pm 0.98$ & $6.55 \pm 0.69$ \\
\hline Taste & $7.60 \pm 0.60$ & $5.95 \pm 0.76$ & $6.10 \pm 0.93$ & $6.55 \pm 0.52$ \\
\hline Flavor & $7.65 \pm 0.67$ & $6.05 \pm 0.10$ & $6.65 \pm 0.95$ & $6.30 \pm 0.80$ \\
\hline Texture & $7.70 \pm 0.80$ & $7.35 \pm 0.75$ & $6.50 \pm 0.95$ & $6.10 \pm 0.79$ \\
\hline $\begin{array}{c}\text { Over all } \\
\text { acceptability }\end{array}$ & $7.65 \pm 0.81$ & $7.00 \pm 0.26$ & $6.70 \pm 0.92$ & $6.40 \pm 0.88$ \\
\hline
\end{tabular}

Table.4 Organoleptic evaluation of potato peel chappati RTE millet mi

\begin{tabular}{|c|c|c|c|c|}
\hline Criteria & Standard & Variation 1 & Variation 2 & Variation 3 \\
\hline Appearance & $7.95 \pm 0.60$ & $6.90 \pm 0.79$ & $7.40 \pm 0.95$ & $7.20 \pm 0.95$ \\
\hline Color & $7.25 \pm 0.79$ & $7.45 \pm 0.89$ & $7.60 \pm 0.68$ & $6.95 \pm 0.78$ \\
\hline Taste & $7.65 \pm 0.67$ & $6.60 \pm 0.60$ & $6.80 \pm 0.83$ & $6.60 \pm 0.82$ \\
\hline Flavor & $7.55 \pm 0.60$ & $6.90 \pm 0.85$ & $6.60 \pm 0.60$ & $6.90 \pm 0.83$ \\
\hline Texture & $6.90 \pm 0.72$ & $7.15 \pm 0.84$ & $7.00 \pm 0.92$ & $6.10 \pm 0.91$ \\
\hline $\begin{array}{c}\text { Over all } \\
\text { acceptability }\end{array}$ & $7.90 \pm 0.85$ & $7.05 \pm 0.94$ & $7.20 \pm 0.89$ & $6.10 \pm 0.71$ \\
\hline
\end{tabular}

Table.5 Organoleptic evaluation of cucumber peel adai RTE millet mix

\begin{tabular}{|c|c|c|c|c|}
\hline Criteria & Standard & Variation 1 & Variation 2 & Variation 3 \\
\hline Appearance & $8.0 \pm 0.46$ & $8.15 \pm 0.59$ & $8.15 \pm 0.93$ & $6.70 \pm 0.92$ \\
\hline Color & $8.15 \pm 0.67$ & $8.35 \pm 0.59$ & $7.90 \pm 0.83$ & $6.80 \pm 0.62$ \\
\hline Taste & $8.15 \pm 0.81$ & $8.35 \pm 0.75$ & $8.10 \pm 0.66$ & $6.70 \pm 0.57$ \\
\hline Flavor & $8.20 \pm 0.70$ & $7.70 \pm 0.80$ & $8.00 \pm 0.64$ & $6.60 \pm 0.60$ \\
\hline Texture & $8.10 \pm 0.72$ & $7.90 \pm 0.85$ & $8.05 \pm 0.54$ & $6.95 \pm 0.76$ \\
\hline $\begin{array}{c}\text { Over all } \\
\text { acceptability }\end{array}$ & $8.05 \pm 0.60$ & $8.25 \pm 0.64$ & $8.15 \pm 0.93$ & $6.80 \pm 0.70$ \\
\hline
\end{tabular}


Table.6 Organoleptic evaluation of cucumber peel vegetable pulav RTE millet mix

\begin{tabular}{|c|c|c|c|c|}
\hline Criteria & Standard & Variation 1 & Variation 2 & Variation 3 \\
\hline Appearance & $8.35 \pm 0.49$ & $8.45 \pm 0.60$ & $6.75 \pm 0.55$ & $6.55 \pm 0.51$ \\
\hline Color & $8.45 \pm 0.51$ & $8.50 \pm 0.51$ & $6.90 \pm 0.79$ & $6.60 \pm 0.50$ \\
\hline Taste & $8.40 \pm 0.50$ & $8.45 \pm 0.60$ & $6.90 \pm 0.64$ & $6.55 \pm 0.60$ \\
\hline Flavor & $8.65 \pm 0.49$ & $8.45 \pm 0.51$ & $7.15 \pm 0.88$ & $6.05 \pm 0.69$ \\
\hline Texture & $8.35 \pm 0.67$ & $8.20 \pm 0.70$ & $6.60 \pm 0.50$ & $6.40 \pm 0.60$ \\
\hline $\begin{array}{c}\text { Over all } \\
\text { acceptability }\end{array}$ & $8.43 \pm 0.50$ & $8.35 \pm 0.75$ & $7.15 \pm 0.67$ & $5.90 \pm 0.97$ \\
\hline
\end{tabular}

Table.7 Organoleptic evaluation of cucumber peel chappati RTE millet mix

\begin{tabular}{|c|c|c|c|c|}
\hline Criteria & Standard & Variation 1 & Variation 2 & Variation 3 \\
\hline Appearance & $7.75 \pm 0.64$ & $7.30 \pm 0.86$ & $6.75 \pm 0.64$ & $7.20 \pm 0.41$ \\
\hline Color & $7.85 \pm 0.81$ & $6.95 \pm 0.83$ & $7.40 \pm 0.60$ & $6.70 \pm 0.80$ \\
\hline Taste & $8.05 \pm 0.51$ & $7.20 \pm 0.77$ & $6.80 \pm 0.70$ & $6.40 \pm 1.10$ \\
\hline Flavor & $7.70 \pm 0.86$ & $7.25 \pm 0.77$ & $7.15 \pm 0.88$ & $6.80 \pm 1.11$ \\
\hline Texture & $7.30 \pm 0.86$ & $7.25 \pm 0.44$ & $6.90 \pm 0.97$ & $6.60 \pm 0.68$ \\
\hline $\begin{array}{c}\text { Over all } \\
\text { acceptability }\end{array}$ & $7.45 \pm 0.76$ & $6.90 \pm 0.85$ & $7.00 \pm 0.92$ & $6.55 \pm 0.94$ \\
\hline
\end{tabular}

Table.8 Overall acceptability of tray dried vegetable peel RTE millet mixes

\begin{tabular}{|c|c|c|c|c|c|}
\hline Tray dried peel & Recipe & Standard & Variation 1 & Variation 2 & Variation 3 \\
\hline \multirow{3}{*}{ Potato } & Adai & $8.50 \pm 0.61$ & $8.20 \pm 0.62$ & $7.40 \pm 0.88$ & $6.80 \pm 0.89$ \\
\cline { 2 - 6 } & $\begin{array}{c}\text { Vegetable } \\
\text { pulav }\end{array}$ & $7.65 \pm 0.81$ & $7.00 \pm 0.26$ & $6.70 \pm 0.92$ & $6.40 \pm 0.88$ \\
\cline { 2 - 6 } & Chappati & $7.90 \pm 0.85$ & $7.05 \pm 0.94$ & $7.20 \pm 0.89$ & $6.10 \pm 0.71$ \\
\hline \multirow{3}{*}{ Cucumber } & Adai & $8.05 \pm 0.60$ & $8.25 \pm 0.64$ & $8.15 \pm 0.93$ & $6.80 \pm 0.70$ \\
\cline { 2 - 6 } & $\begin{array}{c}\text { Vegetable } \\
\text { pulav }\end{array}$ & $8.43 \pm 0.50$ & $8.35 \pm 0.75$ & $7.15 \pm 0.67$ & $5.90 \pm 0.97$ \\
\cline { 2 - 6 } & Chappati & $7.45 \pm 0.76$ & $6.90 \pm 0.85$ & $7.00 \pm 0.92$ & $6.55 \pm 0.94$ \\
\hline
\end{tabular}

An attempt has been made Banu and Singh (2012) to prepare the multigrain composite and its various functional, nutritional, antioxidant properties have been studied. These multigrain composite mixes have been used for the preparation of food formulations which finds use in the preparation of savory products, snacks, pan cake, snacks, like muruku etc. Research and development work carried out at CFTRI on processing and value addition to sorghum and millets has indicated the possibility of preparation of a new generation products (Meera et al., 2009).

Liu et al., (2011) demonstrated the utility of extrusion processing in incorporating high levels of leafy vegetable ingredient in expanded snacks. The extruded product based on moringa leaf powder and oat flour, had substantially improved macro and micro nutrient profile as compared to commercially available snacks. These 
moringa leaf powder oat flour snacks had at least 20 and 90 per cent fiber and protein respectively, and also lower post coating fat and higher vitamin $\mathrm{A}$, iron and calcium than a typical puffed commercial products. Singh et al., (2013) found that finger millets up to 60 per cent can be successfully incorporated to formulate iron rich namakpar mixes.

These mixes are low cost, nutritious, had good storage stability and were acceptable at both laboratory and field level. These mixes can be successfully used for supplementary programs. Pradeep et al., (2014) revealed that popped sorghum, pearl millet and grain amaranthus can be mixed with expanded legumes to prepare a ready-to-eat snack mix. This mix can be shaped into either laddu, burfi or porridge form, mix contain adequate amount of protein and minerals and was found suitable for feeding children and also people of all age groups.

In conclusion, the study revealed that the RTE millet mixes incorporated with tray dried vegetable peels were well accepted at 5 per cent level of incorporation into the selected recipes. These RTE millet mixes/recipes can be prepared at home scale level by the working mothers, cooked and consumed whenever required. The millet - vegetable peel combo is nutrition rich, calorie dense and packed with antioxidants and phytochemicals. Hence can be consumed by all age groups. Intake of millet - vegetable peel combo must be widely promoted both for its content of fiber and other nutrients.

\section{References}

Abascal, K., Ganora, L. and Yameli, E. 2005. The effect of freeze-drying and its implications for botanical medicine: Areview. Phytotherapy Res., 19: 655-660

Banu., H.N. Itagi and Singh, V. 2012. Preparation, nutritional composition, functional properties and antioxidant activities of multigrain composite mixes, J. Food Sci. Technol., 9(1): 7481.

Beecher, G.R., 2003. An overview of dietary flavonoids nomenclature, occurrence and intake. J. Nutr. 133(10): 324-325.

Brandt, M.A., Skinner, E.Z., and Coleman, J.A. 2003. Texture profile method. $J$. Food Sci., 28; 404-409

Chodak, D.A. 2007. Antioxidant properties of different fruit seeds and peels, Acta Sci. Pol., Technol. Aliment. 6(3): 2936

Dowell, M.D. 2009." A Review of the Fruit and Vegetable Food Chain."63

Hawlader, M.N.A., Ed. Hii, C.L., Jangam, S.V., Chiang, C.L., Mujumdar, A.S. 2013. Drying of food products under inert atmosphere using heat pump, in Processing and drying of foods, vegetables and fruits. 7(1): 69-82.

Henriquez, M., S. Almonacid, M. Lutz, R. Simpson \& M. Valdenegro. 2013. Comparison of three drying processes to obtain an apple peel food ingredient, J. Food, Volume 11(2): http://dx.doi.org/10.1080/19476337.20 12.703693

Jangam, V., Sachin, Chung Lim Law and Arun, S., Mujumdar. 2010. Drying of Foods, Vegetables and Fruits, Volume 1.

Liu, T.J., Wei, Q.K., Liao, C.W., Hang, M.J., Wang, T.H. 2011. Microbiological quality of 18 degrees ready-to-eat food products sold in Taiwan. Int. J. Food Microbiol., 80: 241-250.

Meera, M.S., Ushakumari, S.R., Malleshi, N.G. 2008. A process for the preparation of ready-to-eat expanded 
cereals from millets. Patent No. PCT $\mathrm{WO} / 2008 / 072252$

Minton, E.B.S. 2012. Former ENAFS program coordinator, Department of Family, Youth and Community Sciences, University of Florida Institute of Food and Agricultural Sciences, Gainesville, FL 32611.

Mujumdar, A.S., Wu, Z. 2008. Thermal drying technologies-Cost-effective innovation aided by mathematical modeling approach. Drying Technol., 26: 146-154.

Nazneen, N.B., Handigol, J.A., Bala, R.S., Mal, B., Padulosi, S. 2012. Nutritional and Technological Advancements in the Promotion of Ethnic and Novel Foods Using the Genetic Diversity of Minor Millets in India. Indian $J$. Plant Genet. Resour., 23, 82-86.

Nesrine, G.R., Catherine, B., Nabil, K. and Nourthene, B.M. 2015. effect of Air-Drying temperature on kinetics of quality Attributes of lemon citrus limon cv. lunari) peels. Drying technology. An Int. J., DOI: 10. 1080/07373937.2015.1012266.

Pradeep, P.M., Usha Dharmaraj, B.V. Sathyendra Rao, Amudha Senthil, N. S. Vijayalakshmi, N. G. Malleshi and Vasudeva Singh 2014. Formulation and nutritional evaluation of multigrain ready-to-eat snack mix from minor cereals, J. Food Sci. Technol., 51(12): 3812-3820.

Rahuramulu, N., Madhavan Nair, K., Kalyanasundaram, S. 2003. A Manual of Laboratory Techniques. National Institute of Nutrition, Hydrabad. 2345.

Sablani, S.S. 2006. Drying of fruits and vegetables: Retention of Nutritional/Functional. Drying Technol., 24: 123- 135.

Shi, J., Hongyu, W., Yunsheng, W., Jan, H., Robert, B.M., David, S.E. 2003.
The Maize Low-Phytic Acid Mutant lpa2 Is Caused by Mutation in an Inositol Phosphate Kinase Gene. Plant Physiol., 131: 507-515.

Singh, S., Siraj, P., Shamim, M., Verma, A., Agarwal, A., Srivastava, B. 2013. "Development and Standardization of High Protein Corn Incorporated with Kidney Bean and Lentil Flour, 45 ${ }^{\text {th }}$ Annual National Conference of NIN. 127.

Subramanian and viswananthan. 2007. "A Study on Millets Based Cultivation and Consumption In India", Int. J. Marketing, Financial Service and Management Res., 2(4): 4-5.

Takhellamban, R.D., Chimmad, B.V. 2015. Ready - to - cook millet flakes based on minor millets for modern consumer. J. Food Technol., 4(1): 64-69.

Tasirin, S.M., Puspasari, I., Sahalan, A.Z., Mokhtar, M., Kamal, M., Ghani, A., and Yaakob, Z. 2014. Drying of citrus sinesnsis peels in an inert fluidized bed: kinetics, Microbiological Activity, Vitamin C, and Limeonene Determination. Drying Technology: An Int. J., 32: 497-508.

Tripathy, P.P. and Kumar, S. 2009. Influence of sample geometry and rehydration temperature on quality attributes of potato dried under open sun and mixed-mode solar drying. Int. J. Green Energy, 6: 143-156.

Velazquez, M., Hernandez, A., Martin, A., Aranda, E., Gallardo, G., Bartolome, T., and Codoba, M.G. 2014. Quality assessment of commercial paprika. International assessment of commercial paprikas. Int. Assessment WHO. of commercial paprika, 49: 830-839.

http://www.who.int/elena/titles/fruit_v egetables_ncds/en/ 
Zhang, D. \& Hamauzu, Y. 2004. Phenolic compounds and their antioxidant properties in different

tissues of carrots. Food Agri. Environ., 2: 95-100.

\section{How to cite this article:}

Balasasirekha, R., and Santhoshini, P. 2016. Development of RTE Millet Mixes with Dehydrated Vegetable Peel. Int.J.Curr.Microbiol.App.Sci. 5(11): 24-37.

doi: http://dx.doi.org/10.20546/ijcmas.2016.511.003 